\title{
Guidelines for management of sodium hypochlorite extrusion injuries
}

\author{
S. A. Farook ${ }_{1}^{* 1}$ V. Shah, ${ }^{1}$ D. Lenouvel, ${ }_{1}^{2}$ O. Sheikh, ${ }^{1}$ Z. Sadiq ${ }^{1}$ \\ and L. Cascarini'
}

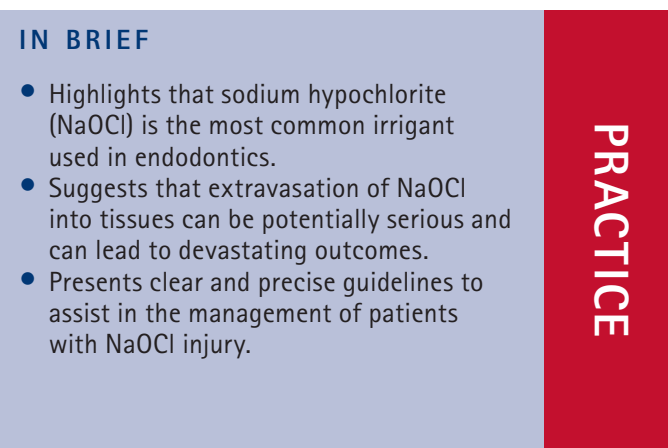

\begin{abstract}
Sodium hypochlorite $(\mathrm{NaOCl})$ is the most common irrigant used in modern endodontics. It is highly effective at dissolving organic debris and disinfecting the root canal system due to the high $\mathrm{pH}$. Extravasation of $\mathrm{NaOCl}$ into intra-oral and extra-oral tissues can lead to devastating outcomes leading to long-term functional and aesthetic deficits. Currently no clear guidelines are available which has caused confusion among the dental and oral and maxillofacial (OMFS) surgical community how best to manage these patients. Following a literature review and considering our own experience we have formulated clear and precise guidelines to manage patients with $\mathrm{NaOCl}$ injury.
\end{abstract}

\section{INTRODUCTION}

The use of irrigants in root canal treatment (RCT) is imperative to its success, with the emphasis of cleaning and over shaping of the root canal system. ${ }^{1}$ Sodium hypochlorite $(\mathrm{NaOCl})$ is the most widely used irrigant, with a concentration ranging from $0.5-5.25 \% .^{2}$ It is bacteriocidal with the capacity to dissolve organic matter, dislodge debris from the root canal system and provide a degree of lubrication whilst shaping the canals during RCT. ${ }^{3-6}$ Although it confers many advantageous properties, care must be taken when using and handling $\mathrm{NaOCl}$ as it is caustic to the vital tissues ${ }^{7,8}$ and related injuries are a recognised risk.

Preventive measures include wearing appropriate personal protective equipment, ensuring the use of a well-sealed rubber dam and high volume suction. ${ }^{9}$ Such precautions help to avoid injuries to skin, eyes, ingestion or even aspiration..$^{10}$ Management of the aforementioned injuries is provided by the Health Protection Agency Compendium of Chemical Hazards. Nevertheless, there is also a risk that $\mathrm{NaOCl}$ may be extruded into the periradicular and soft tissues resulting in an

Department of Oral and Maxillofacial Surgery, The North West London Hospitals NHS Trust, Northwick Park Hospital, Watford Road, Harrow, HA1 3UJ: ${ }^{2}$ Department of Oral and Maxillofacial Surgery, King's College Hospital, Denmark Hill, London, SE5 9RS. ${ }^{*}$ Correspondence to: Mr Shahme A. Farook

Email:safarook@hotmail.com; shahme.farook@nhs.net Tel: +44 (0)208 8643232

\section{Refereed Paper}

Accepted 21 October 2014

DOI: 10.1038/sj.bdj.2014.1099

${ }^{\circ}$ British Dental Journal 2014; 217: 679-684 intense inflammatory response and extensive tissue damage. ${ }^{11}$ Due to the complex anatomy of the head and neck region, such injuries pose potential risk to many important vital structures. ${ }^{12}$ It is therefore important for general dental practitioners (GDP) and endodontists to be well informed how to manage patients with $\mathrm{NaOCl}$ extrusion injuries. Although few recommendations and management strategies have been published ${ }^{9,13}$ a clear precise guideline or protocol for assessing and managing patients with $\mathrm{NaOCl}$ extrusion injury is currently unavailable. Therefore, we have formulated a guideline to facilitate the assessment and management of patients with $\mathrm{NaOCl}$ extrusion injuries, which was developed following analysis of evidence from literature review and from personal experience.

\section{RISK FACTORS}

It is paramount that we understand the factors leading to the risk of extrusion injuries, to adapt and improve personal techniques and minimise risks.

Iatrogenic causes are responsible for majority of extrusion injuries. Inappropriate irrigation techniques, such as the tip of the irrigation syringe being wedged into the root canal preventing the passive flow of irrigant, will result in inappropriate force and irrigating against resistance. ${ }^{13}$ Studies have shown that negative pressure irrigation systems are effective at disinfecting the apical third of the root canal system, whilst minimising the risk of extrusion. ${ }^{14}$ Iatrogenic perforation can also result in communication between the periodontal ligament and root canal system. This can be in the pulp floor during endodontic access or whilst shaping the canal resulting in lateral perforation. In the cases of teeth which have been crowned, endodontic access must be carefully assessed as the crown and root angulations may differ. ${ }^{13}$ During apical preparation of the root canal system, it is important to shape to the apical constriction. In cases where this has been over prepared, the loss of apical constriction will lead to an increased risk of hypochlorite extrusion. ${ }^{9}$ The severity of reactions have been noted to be more severe when increasing concentrations of $\mathrm{NaOCl}$ have been used. ${ }^{15}$ This has led to the debate of the optimum concentration of $\mathrm{NaOCl}$.

Tooth-related factors include endodontic treatment of an immature tooth with a wide apical foramen, ${ }^{16}$ as the apical constriction has not developed the risk of irrigants passing beyond the apex. Resorption of the root may also lead to an enlarged apical foramen. ${ }^{10}$ The anatomical position of teeth relative to alveolar bone is important especially where the apex of the root may be surrounded by thin bone or solely by soft tissue. ${ }^{17}$ In such cases, extrusion of even a small volume of irrigant may lead to symptoms with the potential to spread. It has been postulated that bone density is an important factor as such injuries have been reported to be more common in the maxilla as opposed the mandible, as well as in females compared to males. ${ }^{15}$

\section{GUIDELINE FOR MANAGEMENT OF NAOCL EXTRUSION INJURIES}

Despite careful consideration during RCT, if faced with a suspected $\mathrm{NaOCl}$ related extrusion injury, a thorough clinical and 
radiological assessment is recommended to determine the degree and extent of the injury. This information should assist the clinician to instigate the appropriate management plan to minimise any detrimental effects and to improve the final outcome.

The guidelines presented have been developed through clinical experience in the management of such injuries in a secondary care environment, as well as through reviewing relevant literature. We have proposed to categorise extrusion injuries as mild, moderate and severe according to a patient's signs and symptoms. Each category has been subdivided into immediate, early and late management to optimise the care provided. Although the patients are initially categorised as mild, moderate or severe according their degree of the injury, they can be re-categorised if their signs and symptoms do change.

\section{HISTORY}

According to the guideline a clear concise history would identify patients with a high possibility of extrusion injury.

Recent history of RCT and rapid onset of signs and symptoms have been recognised as cardinal features of extrusion injury. Most patients reviewed in our department have had their RCT carried out on the same day of presentation. They all presented with rapid onset of pain and swelling which helped us to eliminate other possible causes, such as infection which has an indolent presentation when compared to extrusion injury.

The degree of pain needs to be documented using the visual pain score (Fig. 1). Although most patients initially experience severe burning pain; the severity plateaus. We recommend the use of this plateau phase to determine the pain score.

Extrusion into the maxillary antrum ${ }^{18}$ can lead to patients with the smell or taste of bleach ${ }^{19}$ and even nose bleeds. ${ }^{20}$ Patients may also complain of an altered sensation to the areas supplied by the mental nerve or infraorbital nerve, ${ }^{21,22}$ however patients who have undergone RCT on the same day may still be numb from the local anaesthetic. It is also important to take a comprehensive medical history to identify additional patient risk factors which may also need to be taken into account during management.

\section{EXAMINATION}

Systematic approach is recommended to assess extra-oral and intra-oral tissues (Table 1).

\section{Extra-oral examination}

Injuries can have a wide distribution in the extra-oral tissue. $\mathrm{NaOCl}$ results in the dissolution of organic matter and haemolysis, ${ }^{23}$ and

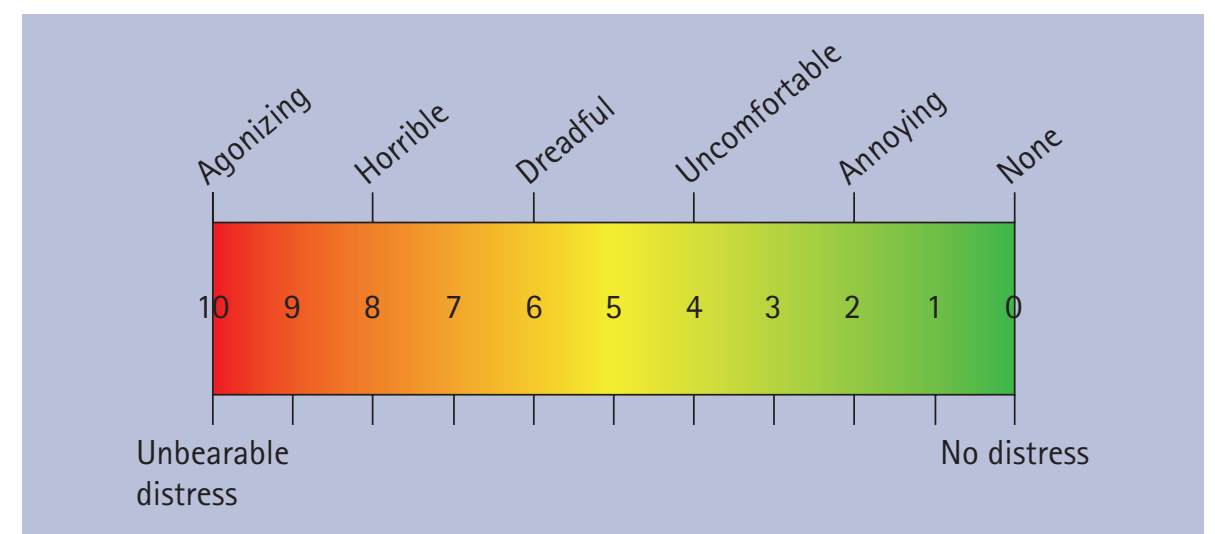

Fig. 1 Visual analogue score for pain

Table 1 Factors to be assessed during examination

\begin{tabular}{l|l}
\hline Extra-oral examination & Intra-oral examination \\
\hline Facial symmetry & Ecchymosis/haematoma \\
Ecchymosis/haematoma & Oedema/swelling \\
Odema/swelling & Ulceration \\
Neurovascular deficit & Necrosis \\
sensory & Neurovascular deficit \\
motor & sensory \\
Dysphagia & Teeth \\
Dyspnoea & \\
\hline
\end{tabular}

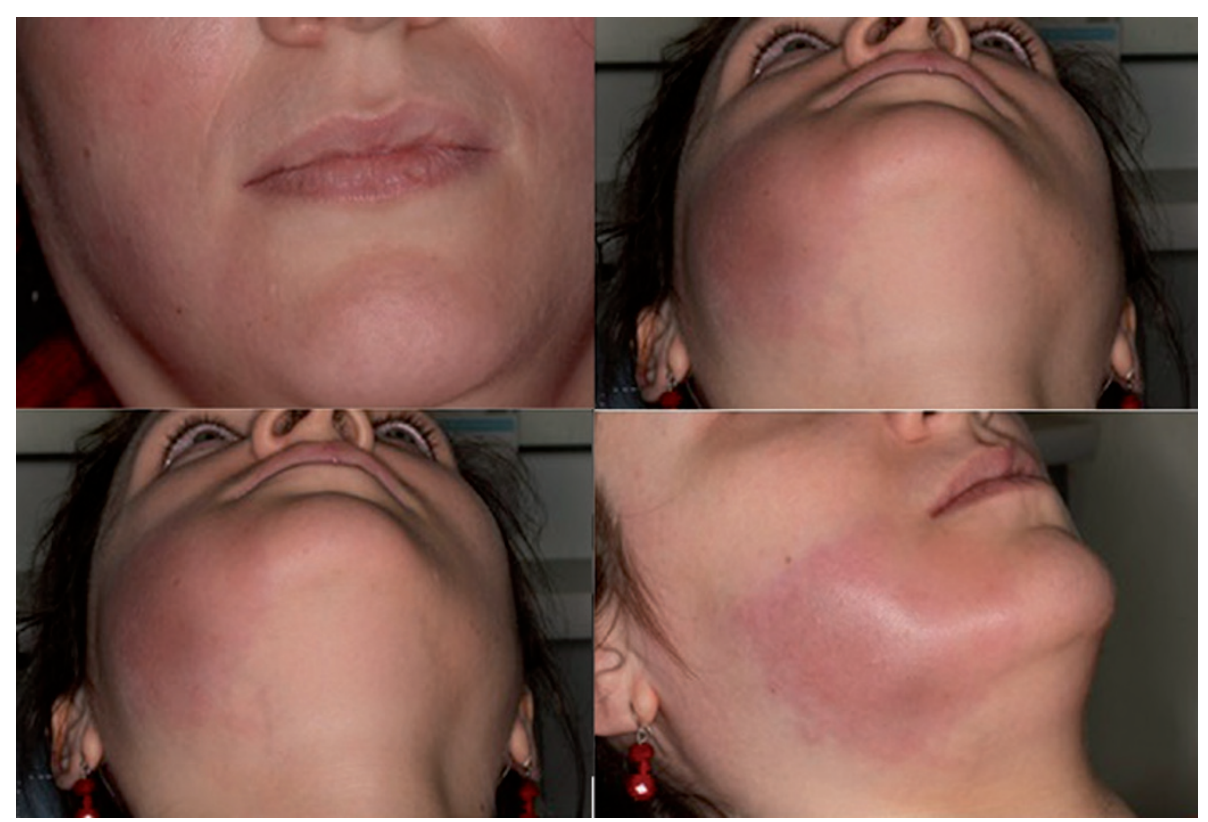

Fig. 2 Facial asymmetry due to swelling and a well delineated area of erythema

facilitates $\mathrm{NaOCl}$ absorption into superficial facial veins which will spread into the soft tissues resulting in a diffuse ecchymosis and swelling (Fig. 2).

It is paramount to objectively evaluate facial swelling to determine the extent of the injury. Szolnoky et al. have presented measurements of distances between six facial planes which can be compared with the opposite side to determine the extent of swelling. ${ }^{24}$ These planes are demonstrated in Figure 3 and include the Tragus-lip junction, Tragus-pogonion, angle-median point of chin, Mandibular angle-lateral canthus,
Mandibular angle-ala nasi and Mandibular angle-lip junction. ${ }^{24}$ It is important to take measurements of both sides, thus allowing the degree of swelling to be compared to the contralateral side in an attempt to quantify this. From our experience when the swelling crosses the midline especially when anterior dentition is involved, these facial measurements proposed does provide objective value to determine the patients progress but might be inadequate to determine the degree of injury. Furthermore, comparison of these reference points will be useful on review appointments to evaluate any changes. 


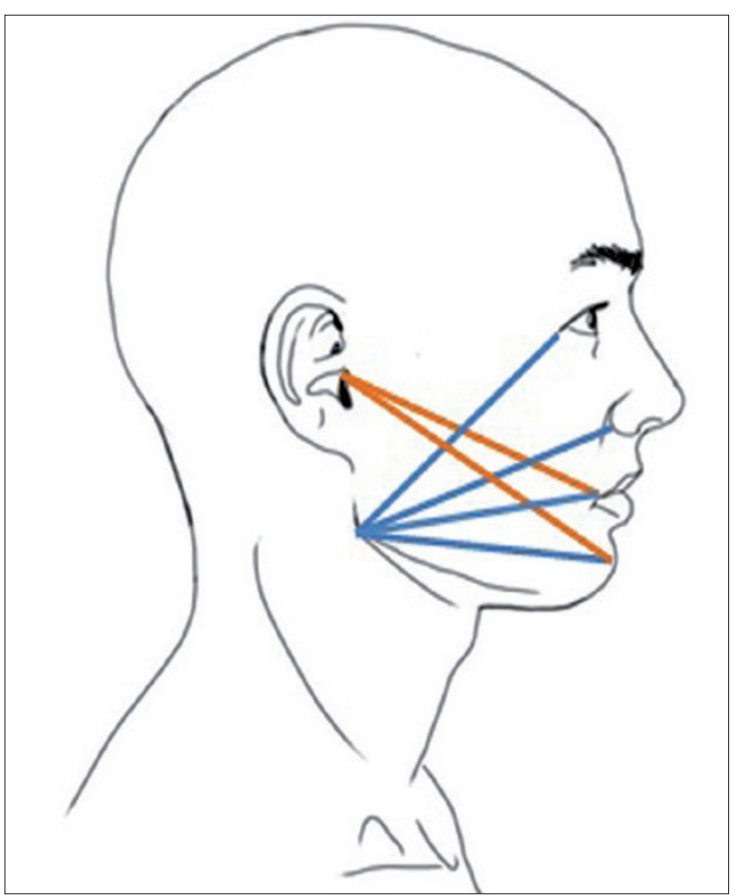

Fig. 3 Six planes used to assess the degree of swelling

Table 2 Summary of findings from history and examination and their associated grading

\begin{tabular}{|c|c|c|c|}
\hline \multirow[t]{2}{*}{ Symptoms } & \multicolumn{3}{|l|}{ Grade of Injury } \\
\hline & Mild & Moderate & Severe \\
\hline Pain (visual pain score) & $0-3$ & $4-6$ & $7+$ \\
\hline Swelling & $<30 \%$ & $30-50 \%$ & $>50 \%$ \\
\hline Ecchymosis & Localised & Diffuse & Diffuse \\
\hline \multirow[t]{4}{*}{ Other } & No ulceration & Intraoral ulceration & Intraoral ulceration \\
\hline & No necrosis & & Intraoral necrosis \\
\hline & & & Airway compromised \\
\hline & & & Neurovascular deficit \\
\hline Pathway & GDP/endodontist & OMFS & OMFS \\
\hline
\end{tabular}

Airway, breathing and swallowing should be assessed to identify any risk to airway as reported by several case reports. ${ }^{25,26} \mathrm{As} \mathrm{NaOCl}$ can spread within the facial tissues, it may result in sensory or motor deficits. Case reports have noted weakness of muscles associated with the buccal and also marginal mandibular branches of the facial nerve, ${ }^{27,28}$ as well as sensory disturbances of mandibular and maxillary branches of the trigeminal nerve. ${ }^{13}$ Therefore, a cranial nerve examination should be undertaken with particular emphasis on the trigeminal nerve and facial nerve.

\section{Intra-oral examination}

During intra-oral examination, swelling should also be evaluated, ensuring that the floor of the mouth is not firm or raised and the effect on adjacent structures. Intra-oral ecchymosis due to extravasation of blood cells into the soft tissues that undergo haemolysis ${ }^{29,30}$ is a common finding. There may be ulceration or necrosis adjacent to the tooth undergoing endodontic treatment, ${ }^{7}$ the extent of which should be accurately documented (Fig. 4). There may also be a sensory neurovascular deficit. The offending tooth and the gingiva is usually tender to percussion. ${ }^{17}$

\section{SEVERITY OF SODIUM HYPOCHLORITE EXTRUSION INJURY}

This importance of a comprehensive history and examination is vital when seeking advice or when referring to secondary care. This information will allow the severity of the injury at presentation to be categorised by assessing these factors as mild, moderate and severe. Although there are many factors a patient may present with, an emphasis on the degree of pain, swelling and ecchymosis will be the main factors which can be used to determine the grading of such injuries (Table 2).

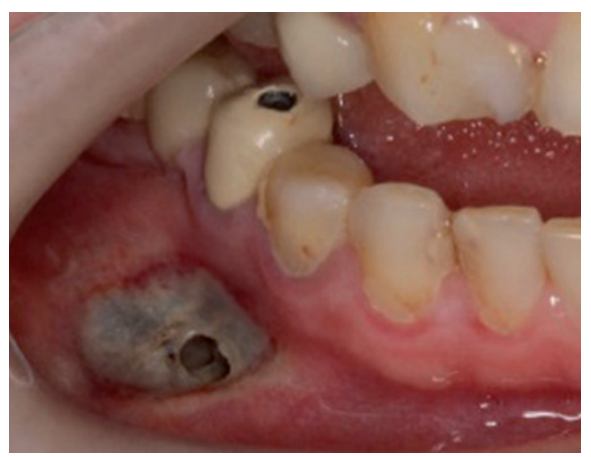

Fig. 4 Intra-oral ulceration with necrosis of the mucosa following $\mathrm{NaOCl}$ injury during root canal treatment of the 45 tooth

\section{Mild injuries}

In milder $\mathrm{NaOCl}$ injuries, the patient may complain of pain or discomfort in the area localised to the tooth undergoing root canal treatment. Although this tooth or adjacent soft tissues may be painful, the patient may describe the pain at the lower end of the visual pain spectrum. As described, $\mathrm{NaOCl}$ injuries respond with an inflammatory reaction, the result being in the nature of swelling. In such patients, the degree of swelling will be less than $30 \%$ relative to the contralateral side with any ecchymosis being localised. These injuries are suitable to be managed in primary care (Table 2).

\section{Moderate injuries}

In patients with moderate $\mathrm{NaOCl}$ injuries, the patient may complain of increased pain and discomfort compared to mild injuries. The hypochlorite may cause an inflammatory reaction which is no longer localised, is now more diffuse in nature and the swelling may be up to 50\% relative to the contralateral side. This is particularly true when $\mathrm{NaOCl}$ diffuses into the superficial facial veins or within the facial spaces. Due to the increased intensity of the reaction within the soft tissues, $\mathrm{NaOCl}$ may cause ulceration intraorally and this is usually present adjacent to the offending tooth (Fig. 4). These injuries are suitable to be managed in secondary care (Table 2).

\section{Severe injuries}

Severe injuries represent the other end of the spectrum of $\mathrm{NaOCl}$ injuries. These contain many features found in moderate injuries; however they are noted with increased severity. The patient may report severe pain, which may be greater than seven on the visual pain score. Extravasation of $\mathrm{NaOCl}$ may result in diffuse swelling and ecchymosis which is greater than 50\%. This may also result in the intra-oral ulceration and necrosis of soft tissues. Although severe injuries appear to be an extension of moderate injuries, there are key features exclusive to the severe grade. 
Inflammatory reaction can also result in oedema, which may be extra-oral or intraoral as described, and can compromise the airway. Motor and sensory neurovascular deficits may occur and are another exclusive feature of severe injuries. These injuries are suitable to be managed in secondary care (Table 2).

\section{TREATMENT}

The guideline for the management of hypochlorite extrusion injuries has divided treatment in two modalities;

- Relative to severity of injury

- Relative to the time of injury and includes immediate, early and late treatment (Appendix 1).

\section{Mild injuries}

\section{Immediate treatment}

This involves treatment within 24 hours following injury. As the severity of the reaction is also linked to the concentration of $\mathrm{NaOCl}$ used, dilution by irrigating the canals with copious amounts of water or saline is recommended. Pain is perhaps the most common symptom and adequate pain relief should be prescribed..$^{9,12}$ In mild injuries over-the-counter analgesia (OTC), or analgesia recommended in the Dental Practitioners Formulary, should be sufficient to manage symptoms. In order to reduce swelling, a combination of nonsteroidal anti-inflammatory drugs (NSAIDs) and cold compresses should to be used. ${ }^{31}$

Radiographic investigations in the form of periapical radiogrpahs or dental panoramic tomography should be taken to identify a cause for the extrusion injury and would also be useful in future management. Canals could be left open to drain and should be revisited regularly over the next few days prior to placement of a proximal seal. External cold compressions could be useful.

\section{Early treatment}

This involves management within the first week following immediate treatment and aims to stabilise the patient following injury prior to any definitive treatment to the tooth. During this period, cold compresses are changed to warm towel compresses to stimulate the local circulation. ${ }^{31}$ If the tooth is deemed to be unrestorable due to gross perforation or pathological fracture secondary to resorption, extraction may the treatment of choice. It is important to regularly review the patient during this period to ensure that any worsening of symptoms is acted on promptly.

\section{Late treatment}

This is long-term treatment which can be carried out once soft tissues have been stable and

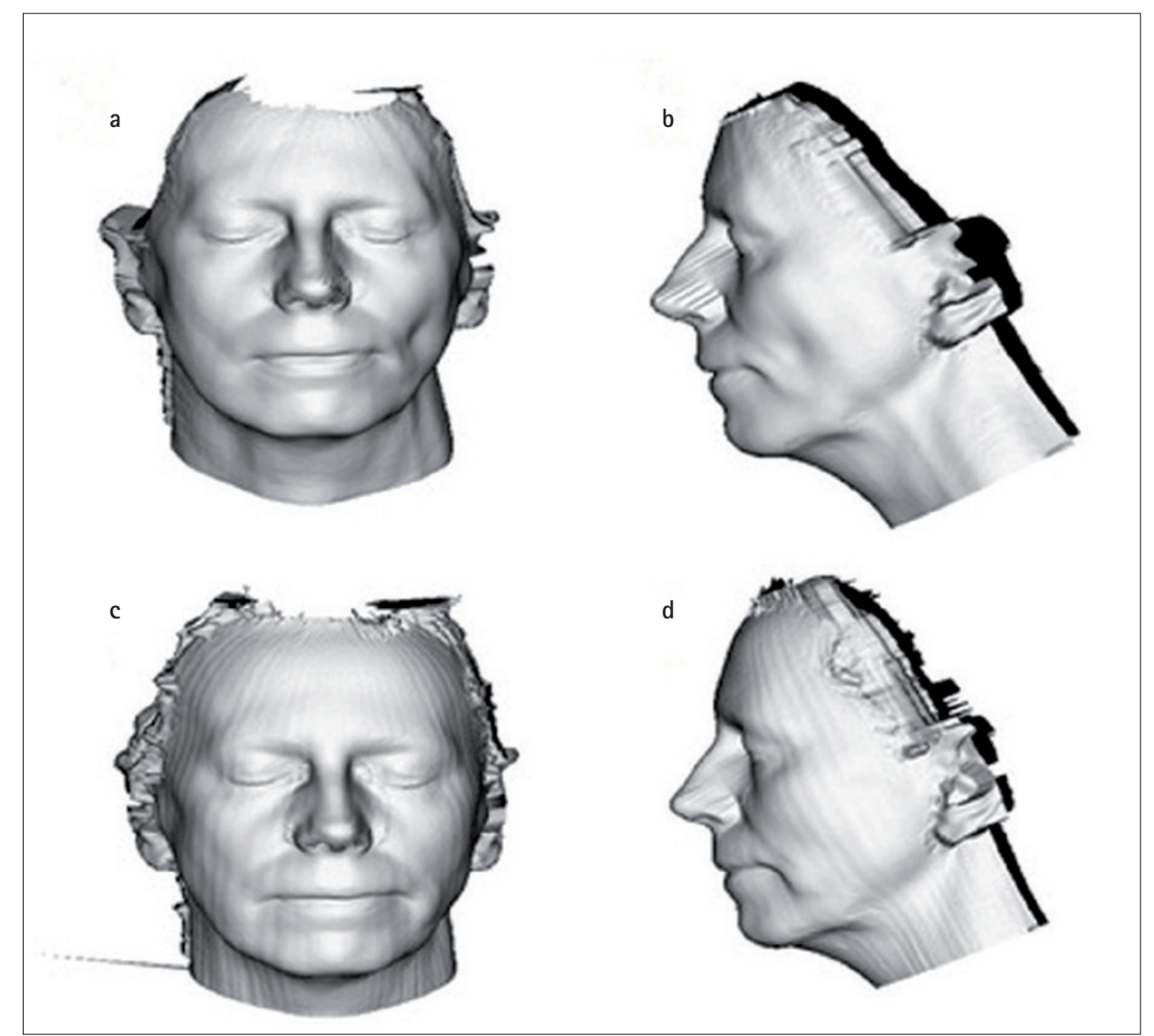

Fig. 5 a) pre-operative frontal and b) side views showing the facial defect in the left cheek before coleman fat transfer; c) post-operative frontal and d) side views showing the improvement in the facial defect in the left cheek after coleman fat transfer

show signs of healing. If completion of root canal treatment is the treatment of choice, an irrigant other than $\mathrm{NaOCl}$ would be advisable.

\section{Moderate injuries}

\section{Immediate treatment}

This is similar to the management of mild extrusion injuries. The degree of pain and discomfort experienced by patients may be higher and may require opiod analgesia ${ }^{13}$ and should be assessed according to the WHO pain ladder. These patients should be discussed with and reviewed by local oral and maxillofacial unit.

Investigations including plain film radiography can be undertaken as per mild injuries. Cone bean computer tomography (CBCT) can be used to assess the effect on surrounding tissues.

\section{Early treatment}

The treatment of moderate injuries includes the same protocol as for mild injuries. Antibiotics may be prescribed if there is any evidence of infection. Due to the effect on the soft tissues, necrotic areas should be debrided to aid healing.

\section{Late treatment}

Similar to mild injuries, if the tooth is restorable, root canal treatment should be completed with an alternative endodontic irrigant. The soft tissue injuries in more severe cases may result in loss of adipose in the facial tissues resulting in cosmetic deformity, ${ }^{13}$ which can be addressed by multiple modalities such as fillers, implants and coleman fat transfer (Fig. 5).

\section{Severe injuries}

\section{Immediate treatment}

Severe cases are better managed within secondary care; hence requires urgent referral to the local OMFS unit. In addition to the prescription of opioids, intra venous (IV) steroids will be required to aid with inflammation. ${ }^{13}$ IV antibiotics should be considered to reduce the risk of secondary infection especially in immunosuppressed patients.

Imaging such as T2 weighted MRI can be used to identify inflamed tissues with good resolution such as bony inflammation ${ }^{13}$, marrow oedema and reactive hyperplasia. Alternatively computerised tomography (CT) can be used to assess the effect on surrounding tissues.

\section{Early treatment}

The early phase of treatment will include that for moderate injuries. In severe cases however there may be need for incision and drainage of any collections which may 
have formed. Since there is evidence of airway obstruction following extrusion injury, regular review is recommended. If there is evidence of airway compromise this should be dealt with a definitive airway if conservative management fails. A case of hypochlorite injury following root canal treatment of lower second molars resulted in a hospital admission as the swelling resulted in respiratory embarrassment which required treatment. ${ }^{25}$

\section{Late treatment}

Severe injuries may be left with significant soft tissue defects due to the loss of adipose in the face and may be corrected using the same techniques as per moderate injuries. These types of injuries may also result in neurovascular deficit. Such deficits may be sensory or motor and will also need to be reviewed at regular intervals and may also require treatment. Neuropathic pain may need pharmacological treatment in a specialist centre. Damage to the branches of facial nerve may need review by OMFS, speech and language therapy and physiotherapy to aid rehabilitation of the patient as there may be an impact on swallowing and speech.

\section{CONCLUSION}

The extrusion of $\mathrm{NaOCl}$ during RCT into the periradicular tissues is a rare occurrence, nevertheless the consequence of which can be potentially serious and can have significant morbidity to the patient. Prior to root canal treatment, the assessment of teeth is important to identify any factors which may predispose extrusion injuries, so that adequate preventive measures can be undertaken. As there is currently little in the way of protocols or guidelines to manage such injuries, we have presented clear guidelines to manage hypochlorite extrusion injuries (Appendix 1). The guideline aims to assist practitioners in the assessment of patients following hypochlorite injuries, with the aim to grade the severity of these injuries into mild, moderate and severe. The presented guidelines aim to help develop standards for future management of sodium hypochlorite extrusion injuries.

1. Harrison J W. Irrigation of the root canal system. Den Clinics North Am 1984; 28: 797-808.

2. Baumgartner J C, Cuenin P R. Efficacy of several concentrations of sodium hypochlorite for root canal irrigation. J Endod 1992; 18: 605-612.

3. Jeansonne M J, White R R. A comparison of $2.0 \%$ chlorhexidine gluconate and $5.25 \%$ sodium hypochlorite as antimicrobial endodontic irrigants. J Endo 1994; 20: 276-278.

4. Clarkson R M, Moule A J. Sodium hypochlorite and its use as an endodontic irrigant. Aust Dent J. 1998; 43: 250-256.

5. Fedorowicz Z, Nasser M, Sequeira-Byron $P$, de Souza $R$ F, Carter B, Heft M. Irrigants for non-surgical root canal treatment in mature permanent teeth. Cochrane Database Syst Rev 2012: 9: CD008948.

6. Zehnder M. Root canal irrigants. J Endod 2006; 32: 389-398.

7. Becker $\mathrm{G} L$, Cohen $S$, Borer R. The sequelae of accidentally injecting sodium hypochlorite beyond the root apex. Report of a case. Oral Surg Oral Med Oral Pathol 1974; 38: 633-638.

8. Senia E S, Marraro R V, Mitchell J L. Rapid sterilization of gutta-percha cones with 5.25 per cent sodium hypochlorite and hydrogen peroxide versus normal saline solution. J Endo 1975; 1: 136-140.

9. Spencer H R, Ike V, Brennan P A. Review: the use of sodium hypochlorite in endodontics - potential complications and their management. Br Dent J 2007; 202: 555-559.

10. Hülsmann M, Hahn W. Review: complications during root canal irrigation - literature review and case reports. Int Endod J 2000; 33: 186-193.

11. Balto $\mathrm{H}, \mathrm{Al}-\mathrm{Nazhan} \mathrm{S}$. Accidental injection of sodium hypochlorite beyond the root apex. Saudi Dent J 2002; 14: 36-38.

12. Zhu W, Gyamfi J, Niu L et al. Anatomy of sodium hypochlorite accidents involving facial ecchymosis a review. J Dent 2013; 41: 935-948.

13. Chaudhry H, Wildan T M, Popat S, Anand R, Dhariwal D. Before you reach for the bleach. Br Dent J 2011; 210: $157-160$

14. Mitchell R P, Yang S, Baumgartner J C. Comparison of apical extrusion of $\mathrm{NaOCl}$ using the EndoVac or needle irrigation of root canals. J Endod 2010; 36: 338-341.

15. Kleier D J, Averbach R E, Mehdipour O. The sodium hypochlorite accident: experience of diplomats of the American Board of Endodontics. J Endod 2008; 34: 1346-1350.

16. Pelka M, Petschelt A. Permanent mimic musculature and nerve damage caused by sodium hypochlorite: a case report. Oral Surg Oral Med Oral Pathol Oral Radiol Endod 2008; 106: e80-e83.

17. de Sermeño R F, da Silva L A, Herrera H, Herrera $H$, Silva R A, Leonardo M R. Tissue damage after sodium hypochlorite extrusion during root canal treatment. Oral Surg Oral Med Oral Pathol Oral Radiol Endod 2009; 108: e46-e49.

18. Zairi A, Lambrianidis T. Accidental extrusion of sodium hypochlorite into the maxillary sinus. Quintessence Int 2008; 39: 745-748.

19. Sleiman P. Irrigation for the root canal and nothing but the root canal.2013. Online information available at http://www.dental-tribune.com/articles/ specialities/endodontics/11609_irrigation_for_the root canal and nothing but the root canal.htm (accessed Novemner 2014).

20. Kavanagh C P, Taylor J. Inadvertent injection of sodium hypochlorite to the maxillary sinus. Br Dent J 1998; 185: 336-337.

21. Becking A G. Complications in the use of sodium hypochlorite during endodontic treatment. Report of three cases. Oral Surg Oral Med Oral Pathol 1991: 71: 346-348.

22. Reeh E S, Messer H H. Long-term paresthesia following inadvertent forcing of sodium hypochlorite through perforation in maxillary incisor. Endod Dent Traumatol 1989; 5: 200-203.

23. Pashley E L, Birdsong N L, Bowman K, Pashley D H Cytotoxic effects of $\mathrm{NaOCl}$ on vital tissue. J Endod 1985; 11: 525-528.

24. S, Szendi-Horváth K, Seres L, Boda K, Kemény L. Manual lymph drainage efficiently reduces postoperative facial swelling and discomfort after removal of impacted third molar. Lymphology 2007; 40: 138-142.

25. Bowden J R, Ethunandan M, Brennan P A. Lifethreatening airway obstruction secondary to hypochlorite extrusion during root canal treatment. Oral Surg Oral Med Oral Pathol Oral Radiol Endod 2006; 101: 402-404.

26. Ziegler D S, Bent G P. Upper airway obstruction induced by a caustic substance found responsive to nebulised adrenaline. J Paediatr Child Health 2001; 37: 524-525.

27. Witton R, Brennan P A. Severe tissue damage and neurological deficit following extravasation of sodium hypochlorite solution during routine endodontic treatment. Br Dent J 2005; 198: 749-750.

28. Witton $R$, Henthorn $K$, Ethunandan M, Harmer $S$, Brennan P A. Neurological complications following extrusion of sodium hypochlorite solution during root canal treatment. Int Dent J 2005; 38: 843-848.

29. Gatot A, Arbelle J, Leiberman A, Yanai-Inbar I. Effects of sodium hypochlorite on soft tissues after its inadvertent injection beyond the root apex. J Endod 1991; 17: 73-74

30. Lam T S M, Wong O F, Tang SYH. A case report of sodium hypochlorite accident. Hong Kong J Emerg Med 2010; 17: 173-176.

31. Kishor N. Oral tissue complications during endodontic irrigation: a literature review. NYState Dent J 2013; 79: 37-42. 


\section{Appendix 1}

\section{Mild}

Mx by GDP/endodontist

\section{Pain 0-3}

Swelling $<30 \%$

Bruising localised

No ulceration/necrosis

\section{Immediate Mx}

- Irrigation with saline/sterile water

- Analgesia (OTC)

- Non-steroidal anti-inflammatory

- Cold compress

- Investigations to identify perforation or root pathology

- Radiographs

- 10 LCPA

- EO DPT

\section{Early Mx}

- Warm towel compress

- Regular review

- Extraction of tooth (if required)

\section{Late $\mathrm{Mx}$}

- Complete RCT with a different irrigant

\section{Moderate}

Refer to OMFS/hospital

Pain 4-6

Swelling 30-50\%

Bruising diffuse

Intra-oral ulceration

\section{Immediate Mx}

- Treatment as for mild injury

- Analgesia (opiods)

- Ref to OMFS

- Investigations to identify perforation or root pathology

- Radiographs

- 10 LCPA

- EO DPT

- $\mathrm{CBCT}$

\section{Early Mx}

- Treatment as for mild injury

- Antibiotics if there is any evidence of infection

- Debridement of necrotic tissue

\section{Late $\mathrm{Mx}$}

- Complete RCT with a different irrigant

- Lipodystrophy

- Fillers

- Implants

- Coleman fat transfer

- Reviewed by OMFS

\section{Severe}

Refer to OMFS/hospital

Pain 7+

Swelling $>50 \%$

Bruising diffuse

Oral ulcerations/necrosis

Airway compromise

Neurovascular deficit

\section{Immediate $\mathrm{Mx}$}

- Treatment as for moderate injury

- IV antibiotics

- IV steroids

- Investigations

○ MRI

○ CT

\section{Early $\mathrm{Mx}$}

- Treatment as for moderate injury

- Incision and drainage of any collection

- Definitive airway (tracheostomy) if airway if compromised (emergency case)

Late $\mathrm{Mx}$

- Lipodystrophy

- Fillers

- Implants

- Coleman fat transfer

- Medical management of neuropathic pain

- Damage to motor nerves requiring advice from Speech and Language Therapy, Physiotherapy due to lip incompetence and poor oral seal

- Surgery 